\title{
Tropicalization of fish assemblages in temperate biogeographic transition zones
}

Article in Marine Ecology Progress Series · May 2014

DOI: $10.3354 /$ meps10749

CITATIONS

9

7 authors, including:

\section{Barbara Horta e Costa}

Centro de Ciências do Mar

22 PUBLICATIONS 71 CITATIONS

SEE PROFILE

\section{Emanuel J. Gonçalves}

MARE - Marine and Environmental Sciences C. . 101 PUBLICATIONS 1,371 CITATIONS

SEE PROFILE
Jorge Assis

Universidade do Algarve

31 PUBLICATIONS 229 CITATIONS

SEE PROFILE

\section{Jennifer E Caselle}

University of California, Santa Barbara

102 PUBLICATIONS 2,585 CITATIONS

SEE PROFILE

Some of the authors of this publication are also working on these related projects: 


\title{
Tropicalization of fish assemblages in temperate biogeographic transition zones
}

\author{
Bárbara Horta e Costa ${ }^{1,2}$, Jorge Assis ${ }^{2}$, Gustavo Franco ${ }^{1}$, Karim Erzini ${ }^{2}$, \\ Miguel Henriques ${ }^{3}$, Emanuel J. Gonçalves ${ }^{1, *}$, Jennifer E. Caselle ${ }^{4}$ \\ ${ }^{1}$ Eco-Ethology Research Unit, ISPA - Instituto Universitário, R. Jardim do Tabaco 34, 1149-041 Lisboa, Portugal \\ ${ }^{2}$ Centre of Marine Sciences, CCMAR, University of Algarve, Campus de Gambelas, 8005-139 Faro, Portugal \\ ${ }^{3}$ ICNF - Instituto de Conservação da Natureza e das Florestas, IP, Parque Natural da Arrábida, Praça da República, \\ 2900-587 Setúbal, Portugal \\ ${ }^{4}$ Marine Science Institute, University of California, Santa Barbara, California 93106, USA
}

\begin{abstract}
Biogeographic transition zones in marine temperate systems are often hotspots of biodiversity, with high levels of resilience to short-term climate shifts due to naturally occurring cyclic oscillations of oceanographic conditions. However, these environments are likely vulnerable to a steady global warming scenario in which these cyclical conditions could be disrupted. Here, we evaluate how changes in local oceanography affect the structure of rocky reef fish assemblages over a period of $50 \mathrm{yr}$ in a biogeographic transition zone. Using a $12 \mathrm{yr}$ time series of rocky reef fish assemblage structure, we identified the set of oceanographic variables that most influenced assemblage dynamics. Descriptive and predictive models (multivariate regression trees) were compared to observed data using the area under the curve. Winter northward wind stress and sea surface temperature (SST) were the most important drivers of change in assemblage structure. Only warmer years had indicator species with warm-temperate or tropical affinities. A fish assemblage 'tropicalization' index was developed in response to both local-spatial resolution and short-term environmental variation (1993-2011), and to regional spatial resolution and long-term SST (1960-2012). Predictive modelling for the last $50 \mathrm{yr}$ revealed that species with tropical affinities have increased in frequency compared to cold-temperate species, coinciding with the trend of increasing mean winter SST. Since the mid-1980s, warm-temperate and tropical species have responded rapidly to more frequent warm winters, suggesting that species distributions are shifting polewards. Our results support a hypothesis that cold species retreat more slowly than the advance of warm species. We discuss the importance of transition zones as 'barometers' of climate change.
\end{abstract}

KEY WORDS: Marine biogeographic transition zone $\cdot$ Resilience $\cdot$ Climate change $\cdot$ Tropicalization Fish assemblages $\cdot$ Species distribution shifts

Resale or republication not permitted without written consent of the publisher

\section{INTRODUCTION}

Global warming effects in the oceans are motivating increased efforts to understand the consequences of climate change on a variety of different marine ecosystems. Increasing temperatures will affect the physiological performance of marine organisms, and may be especially important to ectotherms, which comprise the vast majority of marine species (Pörtner \& Peck 2010, Heath et al. 2012). Marine fish and other organisms are expected to experience altered growth rates, metabolism, reproductive behaviour and outputs, habitat and food requirements, and movement patterns (Perry et al. 2005, Caputi et al. 2010, Pörtner \& Peck 2010), as organisms search for suitable habitats and optimal physiological condi- 
tions (Pörtner \& Peck 2010, Heath et al. 2012). Moreover, early life stages of marine organisms often depend strongly on particular environmental features to disperse, survive and locate suitable settlement habitats, and thus may also be significantly affected by oceanographic changes (Perry et al. 2005, Munday et al. 2008). A primary predicted effect of ocean warming is a shift in species abundance and distribution ranges, which may cause dramatic changes in assemblages and trophic webs (Perry et al. 2005). Latitudinal range shifts in marine species have already been widely described (Perry et al. 2005, Cheung et al. 2009, 2012, Hawkins et al. 2009, Figueira \& Booth 2010, Nicastro et al. 2013, Wernberg et al. 2013) and have been shown to affect ecosystems and fisheries (Sumaila et al. 2011, Cheung et al. 2013). Connectivity patterns of marine systems and species' mobility and dispersal mechanisms result in much larger range increases among some marine fauna when compared to terrestrial species (Heath et al. 2012). Distinguishing between natural oscillations and any added effects of human-induced warming is a major but critical challenge to understanding climate effects in marine ecosystems. This is further complicated by poorly defined baselines and the lack of long-term datasets.

Communities within marine biogeographic transition zones are generally composed of numerous species with overlapping northern and southern range limits (i.e. overlapping warm and cold), few if any local endemics, and often high species diversity. These areas have high potential resilience due to 'normal' cyclic oscillations of oceanographic conditions (Henriques et al. 1999, 2007, Bernhardt \& Leslie 2013). They can act as important field 'laboratories' to detect and distinguish species' responses to natural climatic fluctuations versus human-induced continuous ocean warming. The process of analyzing past trends of species and assemblage structure changes-both in response to natural variability and in particular to more frequent warming periodsmay contribute to a better understanding of future consequences of sustained global warming.

Oceanographic properties that have been shown to drive changes in coastal marine assemblages and species distribution limits include temperature, wind and currents. Wind stress is an important driver of surface currents and upwelling events on the western coasts of the world's continents (Relvas et al. 2007, Sánchez et al. 2007, Bakun et al. 2010). Some systems, such as the Iberian Atlantic west coast, have a seasonal upwelling in which strong southward winds and currents induce Eckman transport east- wards during summer (Relvas et al. 2007, Sánchez et al. 2007), facilitating the movement of deep, cold and nutrient rich-water to the surface, and leading to a decrease in sea surface temperature (SST) and sea surface height (SSH) as well as an increase in coastal productivity (often tracked by the concentration of chlorophyll $a_{\text {; }}$ Cravo et al. 2010). During winter, weaker southward winds and currents do not sustain upwelling events, and occasional counter currents and northward storms prevail (Sánchez et al. 2007). Similar dynamics occur on the western coasts of North America, South America (Bakun et al. 2010), northwest Africa (Belvèze \& Erzini 1984), South Africa (Hutchings et al. 2009) and New Zealand (Chiswell \& Schiel 2001), and have been shown to drive recruitment dynamics, predator-prey relationships and assemblage structure (Menge \& Menge 2013).

The importance of oceanographic drivers measured at small spatial scales on marine assemblages is, in general, less well understood than regional or even global effects (Caselle et al. 2010, Selig et al. 2010). The goals of this study are (1) to evaluate the importance of local-scale oceanographic variables to fish assemblage structure, and their relationship with regional and large-scale climatic features in a temperate biogeographic transition zone, and (2) to hindcast their influence on fish assemblage structure over the last 50 yr. We investigated average conditions, but also extremes and variance in ocean conditions since either may be an even stronger driver of ecosystem-level changes than average conditions. To better understand the inter-annual variability in the composition of fish assemblages relative to oceanographic features, we identified the climatic affinity of species that characterized distinct oceanographic conditions (indicator species), and then evaluated patterns of change through time using a tropicalization index, accounting for species with expected distribution limits in the study region.

\section{MATERIALS AND METHODS}

\section{Study area}

The west coast of Portugal is an important temperate biogeographic transition zone (Henriques et al. 1999, Lima et al. 2007). Seasonal variability in oceanographic conditions has been well studied in these waters (Relvas et al. 2007, Sánchez et al. 2007). Ecologically, this region marks the northern and southern distribution limits of numerous species with 

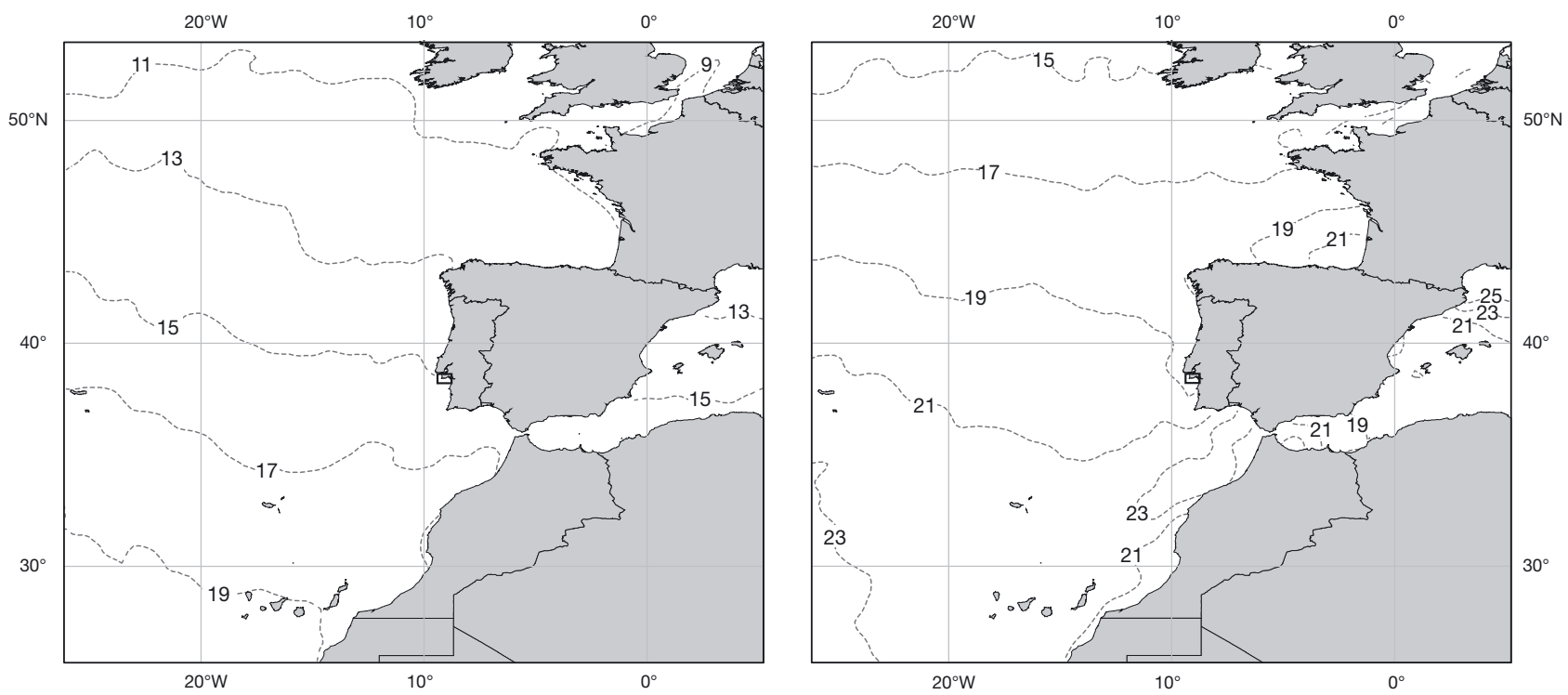

Fig. 1. Study area (Arrábida Marine Park, Portugal; small square). Mean winter (December of the previous year to April; left panel) and summer (June to September; right panel) sea surface temperature (SST; ${ }^{\circ} \mathrm{C}$ ) for the period 1992 to 2012 is shown

warm and cold affinities, respectively (Henriques et al. 1999, 2007, Lima et al. 2007). This area is also near the northern limit of northeast Atlantic upwelling events. The importance of the large-scale North Atlantic Oscillation (NAO) index in driving interannual variability of this region has also been described (Hurrell 1995, Henriques et al. 2007). However, the effect of local-scale (defined here as a $9 \mathrm{~km}$ grid) oceanographic drivers on the composition of fish assemblages has not yet been assessed in this region. The Arrábida Marine Park is a $38 \mathrm{~km}$ stretch of coastline $\left(53 \mathrm{~km}^{2}\right)$ on the west coast of Portugal (Fig. 1). The habitats present in this park support a high diversity of algae, invertebrates and fish, totalling more than 1320 marine species (Henriques et al. 1999, Arrábida Marine Park Authority/ICNF pers. comm.), making this area an important hotspot of biodiversity for this biogeographic region (Henriques et al. 1999).

\section{Data collection}

Fish assemblages were surveyed by underwater visual census using SCUBA from May 1992 to December 2002 (Henriques et al. 2007). We made approximately 30 dives $\mathrm{yr}^{-1}$ with each dive lasting $60 \mathrm{~min}$, beginning in the sandy area $10 \mathrm{~m}$ beyond the rocky substrate and ending at the intertidal, thus covering different depths in a survey perpendicular to the coast. Surveys were carried out by 2 divers, each searching all available habitats and recording every species encountered (presence-absence). This procedure was repeated in 2010 ( $\mathrm{n}=36$ dives).

Fish species were grouped by their climatic affinity following Henriques et al. (2007). These authors classified fish biogeographic climatic affinities as tropical (Tr), warm-temperate (WT), temperate $(\mathrm{T})$, coldtemperate (CT) and eurythermic (E) based on species distributions. When taxa could not be identified to the species level, the genus or family was only considered in the analysis if co-occurring species had the same climatic affinity (see Table S1 in the Supplement at www.int-res.com/articles/suppl/m504 p241_supp.pdf).

Local-scale oceanographic data was obtained from 1992 to 2011 for a location at the centre of the marine park included in a $9 \mathrm{~km}$ resolution grid (representative of local conditions). Local-scale variables (see Table S2 in the Supplement) included SST $\left({ }^{\circ} \mathrm{C}\right)$, eastward (U) and northward (V) wind stress (WindSt) components $\left(\mathrm{N} \mathrm{m}^{-2}\right)$, significant wave height $\left(\mathrm{SWH}_{i}\right.$ $\mathrm{m}), \mathrm{SSH}(\mathrm{m})$ and chlorophyll a (Chla; $\mathrm{mg} \mathrm{m}^{-3}$, only available from 1997 onwards). Two seasons were considered (Henriques et al. 2007): winter (from December of the previous year to April), and summer (June to September). For each oceanographic variable, different metrics (e.g. winter mean, min., max., etc.) were calculated and evaluated in order to explore the influence of each metric on the interannual variability in the composition of the fish assemblages (see Table S2). 
In addition to the local-scale variables, mean NAO was also obtained annually for winter and summer from the NOAA (Table S2) to understand the role of this large-scale index in the fish assemblages' variability, and its relationship to local oceanographic variables. Since our first aim was to assess the influence of local-scale variables in fish assemblages, this large-scale index had to be modelled separately. A dummy variable for seasonal NAO was used to refer to positive NAO (1) and negative NAO (0). Strong positive NAO values indicate cold years in southwest Europe and the Mediterranean, while negative NAO values indicate warm years (Hurrell 1995).

Data for most local-scale variables were not available prior to 1992 (Table S2). Therefore, to create a long time series for use in hindcasting fish assemblage structure, we used regional-scale data for SST and wind stress from the International Comprehensive Ocean-Atmosphere Data Set (ICOADS; icoads. noaa.gov) ( $1^{\circ}$ grid resolution), which is available for the period 1960 to 2012 (Table S2). The NAO data was also obtained for this long-term period.

\section{Data analysis}

\section{Descriptive models}

To understand which local-scale oceanographic variables influenced the presence and absence of rocky reef fish species, multivariate regression trees (MRT) were run using multivariate partitioning (De'Ath 2002; 'mvpart' package v1.6-0; R Development Core Team 2012). A model was run for each of the 6 explanatory variables (SST, WindStV, WindStU, $\mathrm{SWH}, \mathrm{SSH}, \mathrm{Chla})$ to choose which of the 12 derived metrics of the variable (e.g. min., mean, max., etc.; Table S2) were the best predictors. This step prevented the generation of an excessively large matrix of collinear variables. The NAO predictors described above were not included in the 'local' model run, but were tested separately. The purpose was to compare the influence of local versus large-scale ocean variables on the rocky fish assemblage.

All non-collinear (i.e. correlations below 10.6I) combinations of variables were run to choose the set of variables that minimized the cross-validated relative error (CVRE; De'Ath 2002) of the tree. This process was repeated 1000 times to increase confidence in the model choice. The final model was chosen as the one with the lowest CVRE. When different sets of variables had the same CVRE, they were compared based on the relative error. The most frequently selected model (i.e. with the lowest CVRE and relative error) was considered the best model. A separate alternative model with similar characteristics but with the main explanatory variable collinear with that of the best model was also obtained.

\section{Indicator species}

Species that characterize a group (in this case groups created by the MRT analysis) were identified through an indicator species index (defined by Dufrêne \& Legendre 1997 and described and applied to MRTs by De'Ath 2002). The indicator index is based on the relative abundance (also adapted to presence and absence) and frequency of occurrence of each species, varying from 0 to 1 . If a species occurs in one group but is absent from the others, its indicator value (I.V.) is 1 (discriminant species), whereas if a species is absent within a group its I.V. is 0 (De'Ath 2002). Indicator species from each tree split (branches of the tree) and leaf (final partition groups), and discriminant species (max. I.V.) for each tree node (where each branch splits in 2) were calculated for the model selected using MVPARTwrap package v0.1-9 (R Development Core Team 2012).

The contribution of individual species (percentage of explained variance) to each split and to the total tree was also computed. Species with zero contributions to any split are the ubiquitous species present throughout years.

\section{Predictive models}

Species hindcasting was modelled using the set of local-scale explanatory variables from the best MRT descriptive model selected for the short-term period (1993-2011). Long-term hindcasting (beyond 1992) could not be done using local-scale oceanographic variables, since they were not available prior to that year. However, since the purpose of this study was to detect fish assemblage responses to local drivers, we used those regional $\left(1^{\circ}\right)$ oceanographic variables that were highly correlated with the corresponding localscale drivers as proxies to predict assemblage structure for the long-term analysis (1960-2012).

Pearson's correlations were calculated for the local-scale $(9 \mathrm{~km})$ and regional-scale $\left(1^{\circ}\right)$ datasets of the main oceanographic predictors for the short-term (1993-2011) and the long-term (1960-2012) periods, and for the NAO (large-scale) dataset.

Since the results of the predictive models are a continuous response instead of presence or absence of each species (which was the structure of the ob- 
served data), a threshold for the continuous response had to be defined (Liu et al. 2005). Response values falling above or below a particular value (threshold) are respectively classified as species' presence or absence. Twenty levels of threshold were simulated, and the best threshold was chosen based on the simultaneous maximization of the specificity (proportion of correctly predicted absences) and sensitivity (proportion of correctly predicted presences) of the predictive model (Manel et al. 2001).

The performance of the short- and long-term predictive models was evaluated by measuring the agreement between the observed and modelled assemblages from the common years (1993 to 2002, 2010) through the mean area under the receiveroperated characteristic curve (AUC), as recommended by Allouche et al. (2006). Mean AUC was obtained by averaging AUCs from each year. When a predictive model estimates the presence of a species and that species was observed for that year, the value of AUC is 1 ; AUC is 0.5 if the model fails. A perfect match is considered with AUC values above 0.8 (Hosmer \& Lemeshow 2000).

\section{Assemblage indices}

We developed a 'tropicalization' index (TI) for the fish species data adapted from Wernberg et al. (2013) who measured the proportion of tropical species. In the present study, the tropicalization index was calculated as the ratio between the sum of the Tr and CT species occurring in each year. We used only these 2 groups, since their northern and southern range limits are most likely to occur in this transition zone, and they were previously shown to contribute to distinctive warm and cold fish assemblages among years (Henriques et al. 2007).

The TI was calculated using the observed and modelled annual assemblage data for the local-scale $(9 \mathrm{~km})$ datasets of the best predictive model for the short-term period (1993-2011) and for the related regional-scale $\left(1^{\circ}\right)$ datasets for the long-term period (1960-2012).

\section{RESULTS}

During the 12 yr of underwater surveys, 97 species from 35 families were observed and grouped according to their biogeographic affinities in WT (45 species), T (25 species), Tr (12 species), CT (11 species) and $\mathrm{E}$ ( 4 species). All these species were included in the MRT.

\section{Descriptive models}

From the 6 variables (SST, WindStV, WindStU, $\mathrm{SWH}, \mathrm{SSH}, \mathrm{Chla}$ ) and 12 metrics (see Table S2) tested in the MRTs, mean winter values for WindStV, mean $\mathrm{SSH}$, and minimum SWH were selected as the most important set of explanatory variables for the rocky reef fish assemblages. Except when otherwise stated, wind stress refers to the mean winter northward component of wind stress.

Wind stress was collinear to the mean winter SST (Pearson's $r=0.78, p<0.001$ ), which headed a similar separate model (not shown), and was also considered a best explanatory variable. When modelling NAO alone, the mean winter metric was selected.

The best MRT selected had 3 nodes (zones of the tree where each variable splits into distinct branches) explaining $44.3 \%$ of the total species variance (Fig. 2). This tree was headed by wind stress, explaining $18.4 \%$, with the second and third nodes driven by mean winter $\mathrm{SSH}$ and minimum winter SWH, explaining 13.3 and $12.5 \%$ of species variance, respectively.

Although individual species' contributions to the variance explained by each split were relatively low (up to $2.4 \%$ ), a large number of species contributed to differences among years. In the selected model, 58 species contributed to some (i.e. $>0$ ) of the variance explained by the tree (see Table S3 in the Supplement). The 2 splits arising from the first node (ascribed to wind stress) separated 2 groups associated with positive or negative values of wind stress, respectively.

\section{Indicator species}

Five indicator species ( $3 \mathrm{WT}$ and $2 \mathrm{Tr}$ ) were obtained for the groups created by the first node, all being located on the left branch of the tree (associated with positive wind stress; Fig. 2). Of the 5, Phycis phycis (WT) was the discriminant species (maximum indicator value) of this node. In the final partition, 2 species with tropical affinities were indicators of the left leaf, representing lower wave height and positive northward winds.

\section{Predictive models}

The mean AUC revealed a perfect match (mean AUC $=0.92 \pm 0.03$ ) between observed and modelled fish assemblage data headed by the local-scale 


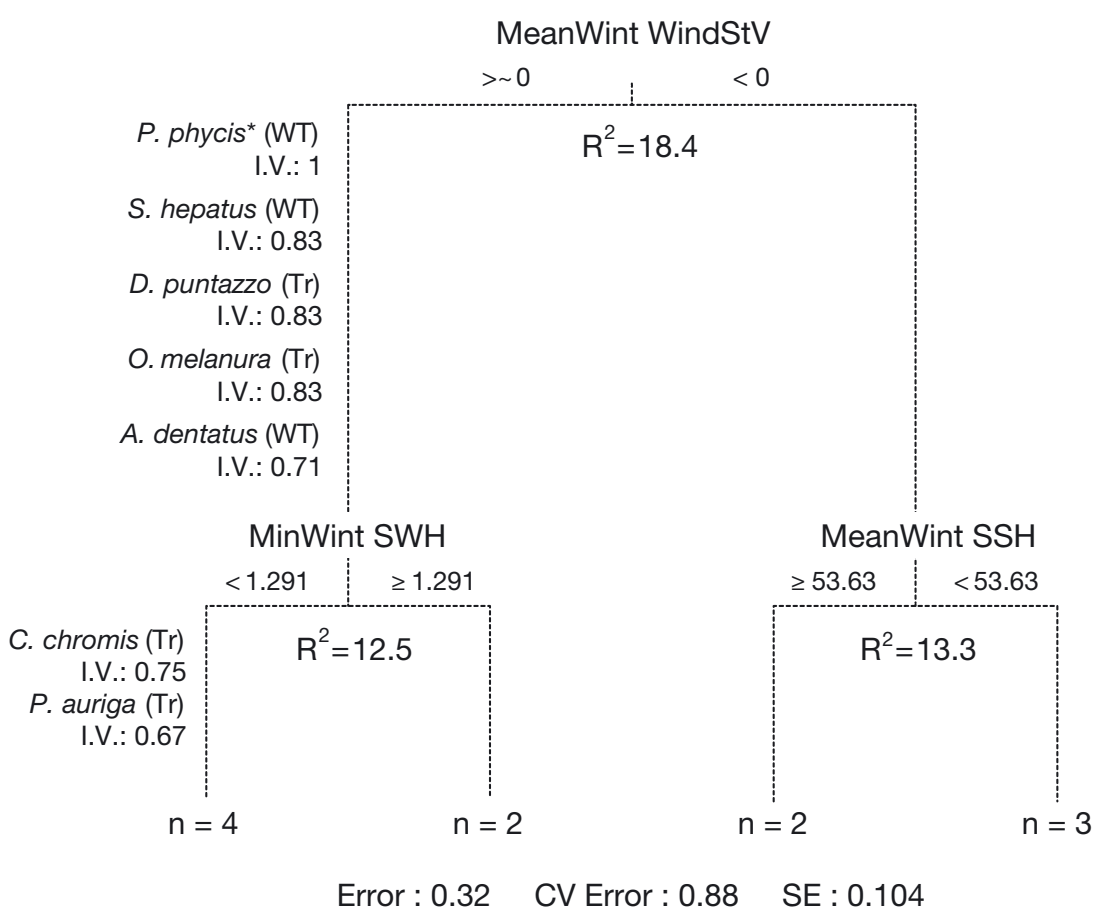

Fig. 2. Best descriptive multivariate regression tree of a $12 \mathrm{yr}$ dataset on presence/absence data of rocky reef fish. The most important predictor variable was mean winter northward component $(\mathrm{V})$ of wind stress (MeanWint WindStV). Mean winter sea surface height (MeanWint $\mathrm{SSH}$ ) and minimum winter significant wave height (MinWint SWH) were also selected predictors. The variance explained $\left(\mathrm{R}^{2}\right)$ by each node is shown. The tree explained $44.3 \%$ of the total species variance. Indicator species of branches and leaves and respective indicator values (I.V.; ${ }^{*}$ refers to node discriminant species) are listed with climatic affinities in parentheses $(\mathrm{WT}=$ warm temperate; $\operatorname{Tr}=$ tropical). The number of sampled years (n) is shown for each life. Genus names are given in full in Table S1 in the Supplement northward wind stress for the short-term period (1993 to 2011).

Since regional-scale and local-scale wind stress values were not well correlated (Pearson's $r=0.52, p$ $=0.098$ ), this variable was not used for the long-term analysis. On the other hand, the 2 datasets were strongly correlated for SST (Pearson's r $=0.94, \mathrm{p}<$ 0.0001), revealing that regional SST values concur with local variability. Since local-scale wind stress and SST were also significantly collinear, the regional-scale $\left(1^{\circ}\right) \mathrm{SST}$ was used as the best driver (and proxy for local drivers) for the long-term assemblage modelling. Validation of the long-term predictions using $1^{\circ} \mathrm{SST}$ also showed a high AUC (0.9 \pm 0.07 ), indicating a high predictive power.

\section{Predictors and assemblage indices}

Trends in local-scale wind stress and SST observed for the period 1993-2011 proved to be similar (Fig. $3 a, b)$. These 2 explanatory variables showed short amplitudes (wind stress $=[-0.05,0.03] \mathrm{N} \mathrm{m}^{-2}$; SST $=$ $\left.[14.21,15.84]^{\circ} \mathrm{C}\right)$.

Both wind stress and SST revealed marginally significant correlations with mean winter NAO values (wind stress-NAO: $\mathrm{r}=-0.61 ; \mathrm{p}=0.05$; SST-NAO: $\mathrm{r}=$ $-0.60, \mathrm{p}=0.05)$.

The TI obtained from predictive models was very similar to the index calculated from observed assem- blages, with only slight differences in 1997, 1998 and 2002 where the modelled TI was lower than the observed one (Fig. 3c). The highest value of the modelled TI (Fig. 3c) was found during the 1996-1998 and 2010 and 2011 periods $(\mathrm{TI}=1.6)$. After the first peak, it decreased over $2 \mathrm{yr}$ and showed a small increase again in 2001 and 2002 (TI = 0.8). The higher values of the index were associated with warmer years (Fig. 3b), which are also years with high values of northward wind stress (Fig. 3a).

Long-term patterns of regional mean winter SST varied between 13.89 and $16.07^{\circ} \mathrm{C}$, with the overall trend suggesting an increase of SST in the last $50 \mathrm{yr}$ (Fig. 4a). The variability between warm and colder periods appeared to become larger and more abrupt after the mid-1980s, with longer periods of higher temperatures.

Long-term patterns of mean winter NAO (range $=$ -1.32 to 1.18 ) also showed inter-annual variability with a period of strong positive NAO at the beginning of the 1990s (Fig. 4b). Although the correlation between winter NAO and regional-scale winter SST was not significant for this long-term period (Pearson's $r=0.065, p=0.65$ ), temporal patterns suggest an inverse relationship through time (Fig. 4a,b).

The long-term prediction of fish assemblage structure revealed more frequent large values of the TI since the mid-1980s, but especially after the mid1990s when the largest index $(\mathrm{TI}=2)$ was reached for the first time in $50 \mathrm{yr}$ (Fig. 4c). 
Fig. 3. Trends of localscale (9 km grid) mean winter (a) northward component of wind stress (MeanWint WindStV); and (b) SST (MeanWint SST) for the period 1993 to 2011; (c) the tropicalization index for the observed $(\mathbf{x})$ and modelled (---) assemblages obtained from the best model selected (headed by MeanWint WindStV)
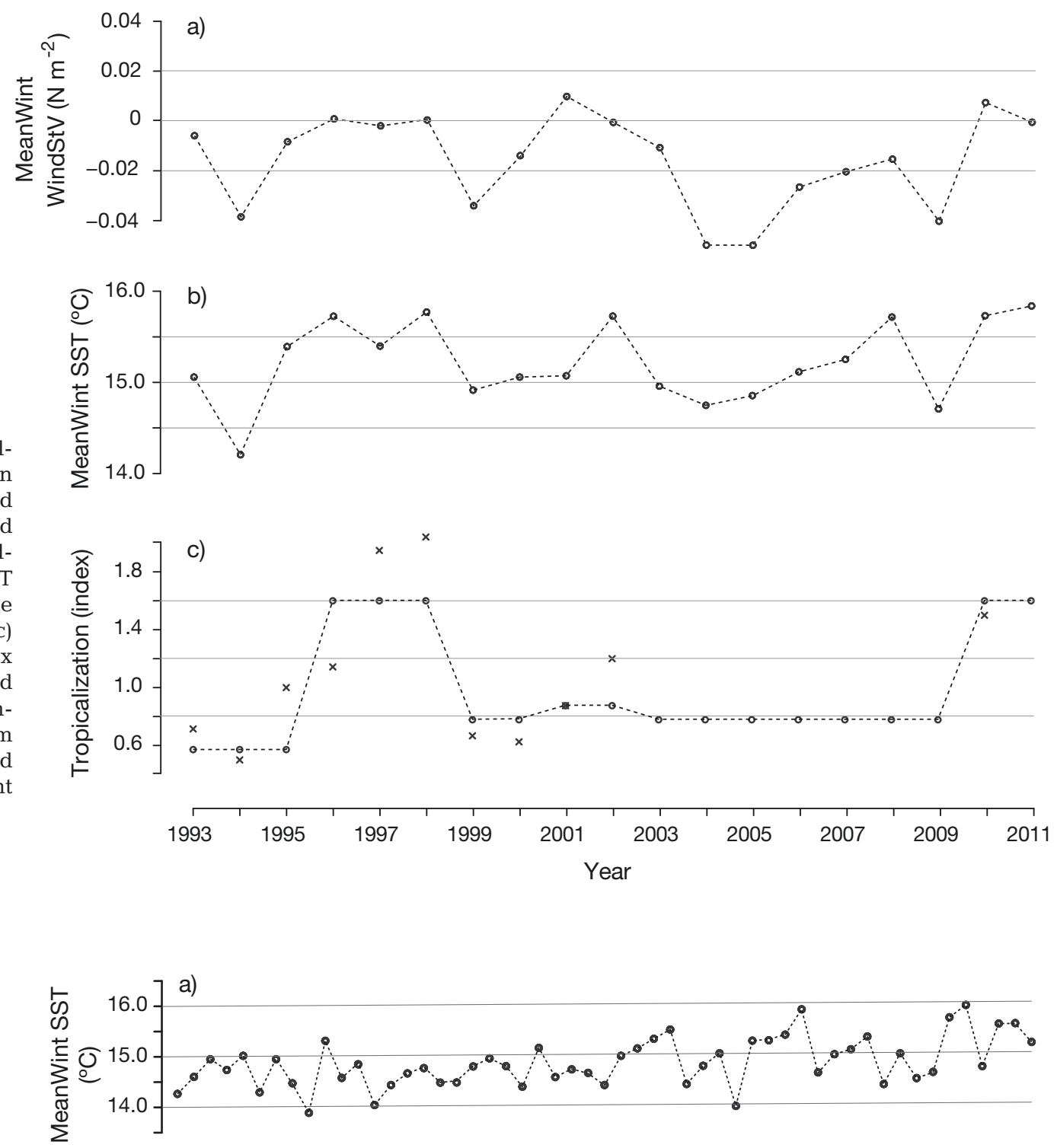

Fig. 4. Trends of regional scale $\left(1^{\circ}\right.$ resolution) mean winter (a) sea surface temperature (MeanWint SST) and (b) North Atlantic Oscillation (MeanWint NAO) for the period 1960 to 2012; (c) tropicalization index for the observed ( $\mathrm{x}$ ) and modelled (-- --) assemblages obtained from the predictive model using long-term SST as explanatory variable
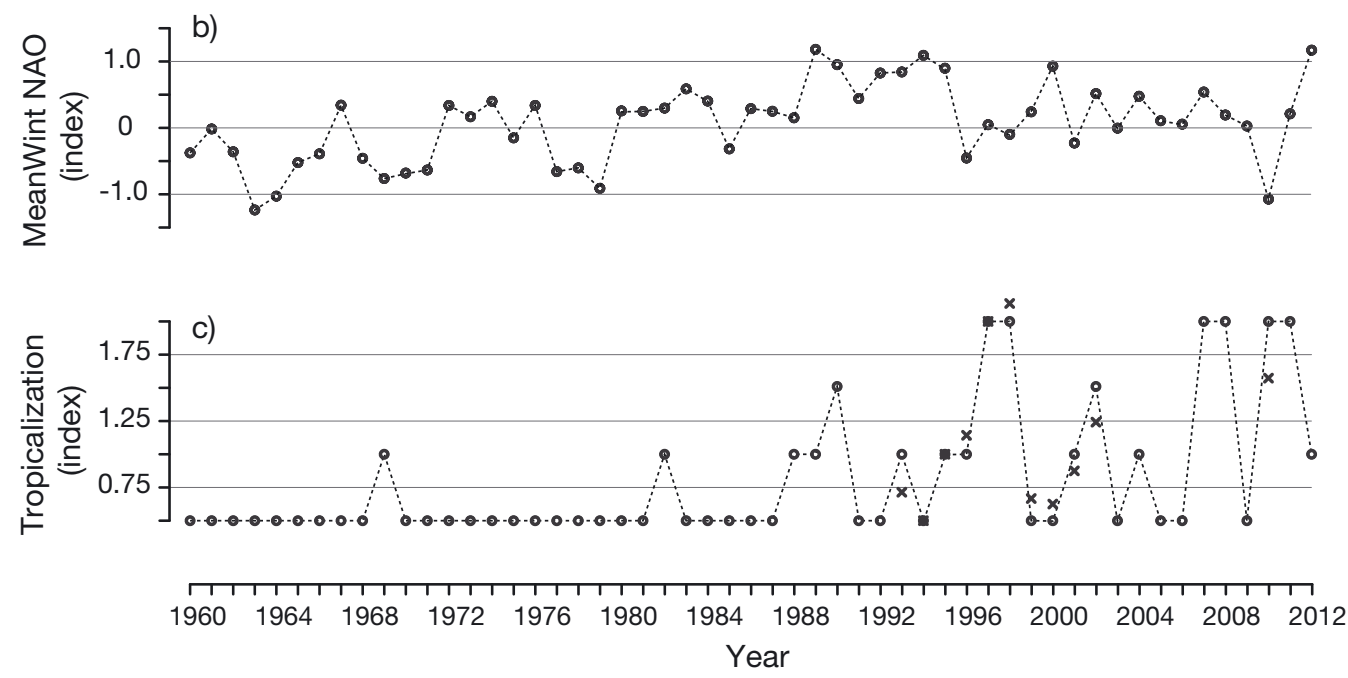


\section{DISCUSSION}

Our study suggests that a 'tropicalization' of fish assemblage structure is underway within a temperate transition zone along the Portuguese west coast, due to more frequent warming events over the last $50 \mathrm{yr}$ corresponding to a period of accelerated warming worldwide (Rosenzweig et al. 2008). These conclusions are supported by the strong influence of local oceanographic variables on assemblage shifts, which show patterns consistent with warming.

The TI detected relevant patterns of change in this assemblage. This index measures relative changes in the proportion of species near the northern or southern edges of their distribution limits, thus considering the species most likely to contribute to changes in the assemblage structure. The index equally weights the contribution of each species, rather than diluting the relevance of low abundance species, which happens when using density or abundance. Range edges expand and contract in response to environmental variations, but are difficult to assess-particularly in the marine environment. A TI is therefore an important tool to detect short-term responses of marine assemblages to climatic variations.

In the same area as this study, Henriques et al. $\underline{(2007)}$ showed that (1) rocky reef fish assemblages changed among years with contrasting climatic features, and (2) winter conditions were the most important drivers of variability in assemblage structure. That study used both regional- and larger-scale climatic and ocean variables, and we have now shown similar results with local-scale predictors. In both cases, the winter NAO showed considerable influence on inter-annual variability in species with distribution limits in this region (Henriques et al. 2007), and was the main large-scale predictor of changes in fish assemblages.

We found that local-scale oceanographic drivers such as WindStV, SST, SSH and SWH better explain fish assemblage patterns of variation. Along-coast winds (which drive coastal upwelling events) are influenced both by local processes and large-scale changes-in particular the location and intensity of subtropical anticyclones which affect NAO patterns (Miranda et al. 2013). Despite this, the relationship between winter NAO and local-scale wind stress and SST was weak, suggesting that local patterns of change in oceanographic variables have a strong influence on assemblage variation.

Fish assemblage composition differed between years in association with mean winter wind stress (i.e. the most important explanatory variable of the best model selected). The resulting indicator species (species that characterize groups formed by the tree analysis) have warm-temperate or tropical affinities and are associated with warmer years where northward winds prevail. On the other hand, no indicator species were associated with winters with strong southward wind stress, and thus colder temperatures.

The rocky fish assemblage in this temperate transition zone is currently comprised mainly of warmtemperate species. This assemblage, however, might have been more influenced by cold-temperate winters in the past decades, during which warm-temperate species may have been limited in their northerly dispersal. This is consistent with the fact that coldtemperate species were not identified as indicator species of assemblage changes. These results point to the importance of integrating local- and largerscale oceanographic variables when studying the dynamics of distribution ranges in marine assemblages (Sánchez et al. 2007, Selig et al. 2010).

How does the taxonomic makeup of fish assemblages change so rapidly? Hawkins et al. (2009) found that warmer years were characterized by an increase of warm-water associated species despite the persistence of cold-temperate ones, possibly due to higher competitive ability and occasionally massive recruitment during spring blooms, as is typical for cold-temperate species. However, after several warm years with consecutively poor recruitment events, cold-temperate species are likely to retreat rapidly. Along the Portuguese coast, Santos et al. (2001) found that winters with strong southward winds and weak but consistent winter upwelling events lead to poor recruitment of sardines in the following months, due to a large offshore transport of eggs and larvae during their spawning season (winter). Additionally, Henriques et al. (2007) suggested that recruitment strength and survival were key to rapid changes in fish assemblages between warm and cold years.

A complementary hypothesis is that recruits and young individuals, which are usually the main drivers for changing distribution limits of marine species (Figueira \& Booth 2010), may shift more rapidly in response to warmer conditions than older, settled adults. This idea is supported by the much larger dispersal ranges of early stages than of adults in demersal fish (Grüss et al. 2011).

The response of cold water species to a continuous but relatively slow warming could show a slower poleward retreat, since even if reproduction is inhibited by temperatures above threshold levels, adults will likely persist until they die (naturally or from 
other causes) as long as conditions are adequate for survival (Pörtner \& Peck 2010). Local extinctions of cold water species may occur due to unsuitable climatic conditions (Malcolm et al. 2002), but will possibly take longer and occur less frequently than the appearance of new tropical immigrants.

Similar to most major upwelling regions of the world, strong southward winds in summer favour offshore Eckman transport in this region, leading to upwelling events and cold coastal waters with increased productivity (Cravo et al. 2010). Cold-temperate species spawning in the spring probably experience suitable conditions during recruitment due to summer and autumn upwelling events, and juveniles and young adults of some species could move to deeper areas in response to thermal stress during warm years. The ability to alter depth ranges as a response to changing temperatures has been shown (Perry et al. 2005, Caputi et al. 2010), and may be an explanation for how some cold-temperate species persist during warm periods. Just as terrestrial plants are predicted to respond to warming by moving polewards and upwards in mountains (Jump et al. 2009), depth shifts may also be more common than previously thought as a response to persistent climate change in marine ecosystems.

SST patterns and modelled fish assemblage predicted by the SST model for the last 50 yr suggest that since the mid-1980s warm winters have increased in frequency, leading to an increased proportion of tropical species in the assemblage. Tittensor et al. (2010) found that SST was the primary environmental predictor related to marine diversity across several taxa at large geographic scales, although available habitat and historical factors also influenced coastal species' distributions. Previous studies for northern Europe described a cold event during 1962 and 1963 followed by cooler conditions until the mid-1980s, after which warming conditions prevailed (Hawkins et al. 2009). This cold period probably affected the climatic conditions of southern Europe and may have influenced the expansion and persistence of the southern distribution limits of coldtemperate species-contributing to the low TI observed for that period. Other studies for the north of Europe described stable biogeographic range limits for several species until the mid-twentieth century (Southward \& Crisp 1956). Studies conducted in our study area in the past showed very abundant canopy-forming brown algae (e.g. Laminaria ochroleuca, Sacchoriza polishides, Fucus vesiculosus), which may have provided structurally complex habitats for fish assemblages (Palminha 1958, Saldanha
1974, Santos 1993). The loss of kelp and fucoid beds and their important habitat function in recent years is likely related to increasing temperature (Assis et al. 2013, Nicastro et al. 2013), affecting both recruitment and resilience (Wernberg et al. 2010). Therefore, both warming conditions and a reduction in habitat complexity may have acted synergistically to contribute to changes in fish assemblage structure found from the mid-1980s onwards.

Regional wind stress was not a good proxy for local patterns in our study, preventing reliable projections using regional-scale data. However, local-scale wind stress was strongly related to local-scale SST, which is correlated to long-term regional SST, suggesting that sea water temperature is a valid proxy for wind stress. With current and future global and regional warming scenarios for the oceans (Bakun et al. 2010, Miranda et al. 2013), it is probable that more frequent, strong northward winds and currents associated with storm events will occur, intensifying their role in the tropicalization of this region and contributing to considerably altered fish assemblages in the near future (Hawkins et al. 2009, Heath et al. 2012). Northward storms may promote nearshore retention of eggs and larvae, contrary to upwelling events (associated with southward winds) which have the opposite effect (Henriques et al. 2007). Northward currents may also facilitate the transport of tropical species into the area. An increase in warm winters will allow tropical fish recruits to overwinter and persist in their marginal distributions, gradually extending their distributions polewards (Perry et al. 2005, Cheung et al. 2009, 2012, Hawkins et al. 2009, Figueira \& Booth 2010, Heath et al. 2012). More frequent extreme climatic events nested within longerterm trends can accelerate shifts in species ranges, and favour the establishment of warmer species due to the persistence of suitable conditions (Cheung et al. 2009, Garrabou et al. 2009, Wernberg et al. 2013).

Temperate transition areas are often considered 'hotspots' of biodiversity since they are typically characterized by complex and diverse habitats, and contain species adapted to heterogeneous inter- and intra-annual oceanographic conditions. In these areas, northern and southern distribution ranges of warm and cold species change with temporal cyclic fluctuations (Henriques et al. 1999). Thus, the most likely pattern for a future persistent warming scenario is the rapid advance of tropical species polewards and the simultaneous, but slower, gradual retreat of cold-water species (Hawkins et al. 2009). Interestingly, most of the species with tropical affinities found in this study have historically local com- 
mercial value (e.g. Baldaque da Silva 1891), which is evidence of their presence in the area in the past. Despite the rare occurrences of adults of tropical species far from their distribution limits (Horta e Costa \& Gonçalves 2013), the tropicalization of this temperate fish assemblage is mainly occurring with species that have historically existed in the region. In fact, a rapid response of fish assemblages to climate change is more probable in areas of continuous and/or contiguous habitats, which facilitate high dispersal rates (Hiddink \& ter Hofstede 2008). A rapid response is also more likely to be detected with the contribution of species having their distribution limits in neighbouring regions. Our findings illustrate the important 'barometer' role of this area for the study of the effects of climate change (Horta e Costa \& Gonçalves 2013). If cyclic fluctuations of climatic conditions remain and cold years return after a warm period, cold species are likely to persist in the region, as they can move deeper and the predominant southward currents transport their propagules from the north. These temporal fluctuations, typical of transition zones, may alleviate some warming effects. This highlights the potential resilience of transition areas to climatic shifts when compared to typical tropical or polar regions, where high rates of extinctions and invasions are very likely (Cheung et al. 2009, Sumaila et al. 2011) and possibly irreversible.

Despite contradictory projections about the intensification or reduction of upwelling with global warming (Bakun et al. 2010), Miranda et al. (2013) predicted a future increase in upwelling events, especially in the northern limit of the Iberian west coast (near Cape Finisterre), where the mean effect may extend hundreds of kilometres. This could mitigate the effect of local warming (Miranda et al. 2013) and facilitate the persistence of cold-temperate species. If this is true, and upwelling events increase in a warmer ocean, such transition zones could have high levels of resilience to climate change. However, although species from these areas show some plasticity in their ability to deal with variable oceanographic conditions, a disruption of the historical cyclic fluctuations due to steady ocean warming could gradually change assemblages until very different assemblages and trophic interactions remain (Perry et al. 2005, Cheung et al. 2012, Heath et al. 2012). Furthermore, synergistic and additive effects on marine assemblages are likely to occur between climate change and other human-induced activities such as overfishing (Griffith et al. 2011). Such impacts may contribute to a decrease in ecosystem resistance, and accelerate the disturbance of assem- blage structure and species interactions (Ling et al. 2009). For example, intensively fished populations were found to be the most susceptible to ocean acidification, revealing that stressed populations show higher vulnerability to climate change (Griffith et al. 2011). Networks of marine protected areas have been suggested to increase the resilience of ecosystems in relation to future warming scenarios, while reducing the impact of fishing and other human uses (Ling et al. 2009, McLeod et al. 2009), possibly mitigating non-linear and unpredictable responses of species and ecosystems in this changing world (Munday et al. 2008).

The tropicalization of coastal fish assemblages could lead to large biological and socio-economic impacts in the near future (Sumaila et al. 2011, Cheung et al. 2012, 2013). To reduce uncertainties in future projections, it is crucial to have an improved understanding of past responses (Pandolfi et al. 2011). With the tropicalization of transition areas becoming more frequent worldwide (Hawkins et al. 2009, Cheung et al. 2012, 2013, Wernberg et al. 2013) and the current rate of human-induced impacts, structural changes to marine assemblages could be very large in the future, disrupting ecosystems and leading to tropical species dominating in previously temperate zones.

Acknowledgements. The authors thank H. Folhas, D. Rodrigues and J. Martins for field support, and ICNF for the marine park support. We also thank C. Syms for valuable suggestions regarding the statistical analysis. This research was funded by Biomares LIFE project (LIFE06 NAT/P/ 000192) and by Fundação para a Ciência e a Tecnologia (FCT) through the project PDCT/MAR/57934/2004 and the Pluriannual Program (R\&D Unit 331/94, PEst-OE/MAR/ UI0331/2011). B.H.C. was supported by a PhD grant from FCT (SFRH/BD/41262/2007) and part of her work was done at the Marine Science Institute of the University of California at Santa Barbara.

\section{LITERATURE CITED}

Allouche O, Tsoar A, Kadmon R (2006) Assessing the accuracy of species distribution models: prevalence, kappa and the true skill statistic (TSS). J Appl Ecol 43: $1223-1232$

Assis J, Castilho Coelho N, Alberto F, Valero M, Raimondi P, Reed D, Serrão EA (2013) High and distinct range-edge genetic diversity despite local bottlenecks. PLoS ONE 8: e68646

Bakun A, Field DB, Redondo-Rodriguez A, Weeks SJ (2010) Greenhouse gas, upwelling-favorable winds, and the future of coastal ocean upwelling ecosystems. Glob Change Biol 16:1213-1228

Baldaque da Silva AA (1891) Estudo actual das pescas em Portugal compreendendo a pesca marítima, fluvial e 
lacustre em todo o continente do reino, referido ao ano de 1886. Imprensa Nacional, Lisboa

Belvèze H, Erzini K (1984) The influence of hydroclimatic factors on the availability of the sardine (Sardina pilchardus Walbaum) in the Moroccan Atlantic fishery. FAO Fish Rep 291:285-328

Bernhardt JR, Leslie HM (2013) Resilience to climate change in coastal marine ecosystems. Ann Rev Mar Sci 5: 371-392

Caputi N, Melville-Smith R, de Lestang S, Pearce A, Feng M (2010) The effect of climate change on the western rock lobster (Panulirus cygnus) fishery of Western Australia. Can J Fish Aquat Sci 67:85-96

Caselle JE, Kinlan BP, Warner RR (2010) Temporal and spatial scales of influence on near-shore fish settlement in the Southern California Bight. Bull Mar Sci 86:355-385

> Cheung WWL, Lam VWY, Sarmiento JL, Kearney K, Watson R, Pauly D (2009) Projecting global marine biodiversity impacts under climate change scenarios. Fish Fish 10: 235-251

> Cheung WWL, Meeuwig JJ, Feng M, Harvey E and others (2012) Climate-change induced tropicalisation of marine communities in Western Australia. Mar Freshw Res 63: 415-427

> Cheung WWL, Watson R, Pauly D (2013) Signature of ocean warming in global fisheries catch. Nature 497:365-368

> Chiswell SM, Schiel DR (2001) Influence of along-shore advection and upwelling on coastal temperature at Kaikoura Peninsula, New Zealand. N Z J Mar Freshw Res 35: 307-317

Cravo A, Relvas P, Cardeira S, Rita F, Madureira M, Sánchez $\mathrm{R}$ (2010) An upwelling filament off southwest Iberia: effect on the chlorophyll $a$ and nutrient export. Cont Shelf Res 30:1601-1613

De'Ath G (2002) Multivariate regression trees: a new technique for modelling species-environment relationships. Ecology 83:1105-1117

Dufrêne M, Legendre P (1997) Species assemblages and indicator species: the need for a flexible asymmetrical approach. Ecol Monogr 67:345-366

> Figueira WF, Booth DJ (2010) Increasing ocean temperatures allow tropical fishes to survive overwinter in temperate waters. Glob Change Biol 16:506-516

Garrabou J, Coma R, Bensoussan N, Bally M and others (2009) Mass mortality in northwestern Mediterranean rocky benthic communities: effects of the 2003 heat wave. Glob Change Biol 15:1090-1103

> Griffith GP, Fulton EA, Richardson AJ (2011) Effects of fishing and acidification-related benthic mortality on the southeast Australian marine ecosystem. Glob Change Biol 17:3058-3074

> Grüss A, Kaplan DM, Hart DR (2011) Relative impacts of adult movement, larval dispersal and harvester movement on the effectiveness of reserve networks. PLoS ONE 6:e19960

> Hawkins SJ, Sugden HE, Mieszkowska N, Moore PJ and others (2009) Consequences of climate-driven biodiversity changes for ecosystem functioning of North European rocky shores. Mar Ecol Prog Ser 396:245-259

> Heath MR, Neat FC, Pinnegar JK, Reid DG, Sims DW, Wright PJ (2012) Review of climate change impacts on marine fish and shellfish around the UK and Ireland. Aquat Conserv 22:337-367

Henriques M, Gonçalves EJ, Almada VC (1999) The conservation of littoral fish communities: a case study at the
Arrábida coast (Portugal). In: Almada VC, Oliveira R, Gonçalves EJ (eds) Behaviour and conservation of littoral fishes. ISPA, Lisbon, p 473-519

Henriques M, Gonçalves EJ, Almada VC (2007) Rapid shifts in a marine fish assemblage follow fluctuations in winter sea conditions. Mar Ecol Prog Ser 340:259-270

Hiddink JG, ter Hofstede R (2008) Climate induced increases in species richness of marine fishes. Glob Change Biol 14:453-460

Horta e Costa B, Gonçalves EJ (2013) First occurrence of the Monrovia doctorfish Acanthurus monroviae (Perciformes: Acanthuridae) in European Atlantic waters. Mar Biodivers Rec 6:e20

Hosmer DW, Lemeshow S (2000) Applied logistic regression, 2nd edn. John Wiley \& Sons, New York, NY

- Hurrell JW (1995) Decadal trends in the North Atlantic Oscillation: regional temperatures and precipitation. Science 269:676-679

Hutchings L, van der Lingen CD, Shannon LJ, Crawford RJM and others (2009) The Benguela Current: an ecosystem of four components. Prog Oceanogr 83:15-32

Jump AS, Matyas C, Penuelas J (2009) The altitude-for-latitude disparity in the range retractions of woody species. Trends Ecol Evol 24:694-701

Lima FP, Ribeiro PA, Queiroz N, Hawkins SJ, Santos AM (2007) Do distributional shifts of northern and southern species of algae match the warming pattern? Glob Change Biol 13:2592-2604

Ling SD, Johnson CR, Frusher SD, Ridgway KR (2009) Overfishing reduces resilience of kelp beds to climate-driven catastrophic phase shift. Proc Natl Acad Sci USA 106: 22341-22345

Liu C, Berry PM, Dawson TP, Pearson RG (2005) Selecting thresholds of occurrence in the prediction of species distributions. Ecography 28:385-393

Malcolm JR, Markham A, Neilson RP, Garaci M (2002) Estimated migration rates under scenarios of global change. J Biogeogr 29:835-849

Manel S, Williams HC, Ormerod SJ (2001) Evaluating presence-absence models in ecology: the need to account for prevalence. J Appl Ecol 38:921-931

McLeod E, Salm R, Green A, Almany J (2009) Designing marine protected area networks to address the impacts of climate change. Front Ecol Environ 7:362-370

> Menge BA, Menge DNL (2013) Dynamics of coastal metaecosystems: the intermittent upwelling hypothesis and a test in rocky intertidal regions. Ecol Monogr 83:283-310

> Miranda PMA, Alves JMR, Serra N (2013) Climate change and upwelling: response of Iberian upwelling to atmospheric forcing in a regional climate scenario. Clim Dyn 40:2813-2824

Munday PL, Jones GP, Pratchett MS, Williams A (2008) Climate change and the future of coral reef fishes. Fish Fish 9:261-285

> Nicastro KR, Zardi GI, Teixeira S, Neiva J, Serrao EA, Pearson GA (2013) Shift happens: trailing edge contraction associated with recent warming trends threatens a distinct genetic lineage in the marine macroalga Fucus vesiculosus. BMC Biol 11:6

Palminha F (1958) As algas marinhas da zona costeira da Arrábida e a sua protecção. In: Liga para a Protecção da Natureza (ed) A serra da Arrábida e a protecção à Natureza. Liga para a protecção da natureza, Lisboa, p 5-23

Pandolfi JM, Connolly SR, Marshall DJ, Cohen AL (2011) Projecting coral reef futures under global warming and 
ocean acidification. Science 333:418-422

Perry AL, Low PJ, Ellis JR, Reynolds JD (2005) Climate change and distribution shifts in marine fishes. Science 308:1912-1915

Pörtner HO, Peck MA (2010) Climate change effects on fishes and fisheries: towards a cause-and-effect understanding. J Fish Biol 77:1745-1779

R Development Core Team (2012) R: a language and environment for statistical computing. R Foundation for Statistical Computing, Vienna

Relvas P, Barton ED, Dubert J, Oliveira PB, Peliz Á, da Silva JCB, Santos AMP (2007) Physical oceanography of the western Iberia ecosystem: latest views and challenges. Prog Oceanogr 74:149-173

Rosenzweig C, Karoly D, Vicarelli M, Neofotis P and others (2008) Attributing physical and biological impacts to anthropogenic climate change. Nature 453:353-357

Saldanha L (1974) Estudo do povoamento dos horizontes superiores da rocha litoral da costa da Arrábida (Portugal). Arquivos do Museu Bocage, Publicação do Museu e Laboratório Zoológico e Antropológico, Faculdade de Ciências de Lisboa, Lisboa

Sánchez RF, Relvas P, Delgado M (2007) Coupled ocean wind and sea surface temperature patterns off the western Iberian Peninsula. J Mar Syst 68:103-127

Santos R (1993) A multivariate study of biotic and abiotic

Editorial responsibility: Konstantinos Stergiou,

Thessaloniki, Greece relationships in a subtidal algal stand. Mar Ecol Prog Ser 94:181-190

Santos AMP, Borges MF, Groom S (2001) Sardine and horse mackerel recruitment and upwelling off Portugal. ICES J Mar Sci 58:589-596

Selig ER, Casey KS, Bruno JF (2010) New insights into global patterns of ocean temperature anomalies: implications for coral reef health and management. Glob Ecol Biogeogr 19:397-411

Southward AJ, Crisp DJ (1956) Fluctuations in the distribution and abundance of intertidal barnacles. J Mar Biol Assoc UK 35:211-229

Sumaila UR, Cheung WWL, Lam VWY, Pauly D, Herrick S (2011) Climate change impacts on the biophysics and economics of world fisheries. Clim Chang 1:449-456

Tittensor DP, Mora C, Jetz W, Lotze HK, Ricard D, Berghe EV, Worm B (2010) Global patterns and predictors of marine biodiversity across taxa. Nature 466:1098-1101

Wernberg T, Thomsen MS, Tuya F, Kendrick GA, Staehr PA, Toohey BD (2010) Decreasing resilience of kelp beds along a latitudinal temperature gradient: potential implications for a warmer future. Ecol Lett 13:685-694

Wernberg T, Smale DA, Tuya F, Thomsen MS and others (2013) An extreme climatic event alters marine ecosystem structure in a global biodiversity hotspot. Nature Clim Change 3:78-82

Submitted: June 11, 2013; Accepted: January 29, 2014 Proofs received from author(s): April 10, 2014 